\title{
A School-Based Measure of Culturally Responsive Practices
}

\author{
Mustafa Asil* \\ Educational Assessment Research Unit, College of Education, University of Otago, Dunedin, New Zealand
}

This study aimed to address a gap in current research on cultural responsiveness by introducing the Culturally Responsive Practices for Māori Scale (CRPMS), a self-report instrument designed to measure schools' culturally responsive practices in relation to Māori students. Within this paper, the development and analysis of the factorial structure and psychometric properties of the CRPMS are presented. The validity evidence findings from this study supported the utility of the CRPMS as a measure of cultural responsiveness for mainstream English-speaking New Zealand schools. Potential uses and applications of the CRPMS by researchers and educational stakeholders are discussed.

Keywords: education for Māori, cultural responsiveness, diversity, equity, inclusiveness

\section{INTRODUCTION}

OPEN ACCESS

Edited by:

Anastasiya A. Lipnevich,

The City University of New York, USA

Reviewed by:

Chad W. Buckendahl, ACS Ventures LLC, USA Jeffrey K. Smith,

University of Otago, New Zealand

*Correspondence: Mustafa Asil mustafa.asil@otago.ac.nz

Specialty section:

This article was submitted to Assessment, Testing and Applied Measurement, a section of the journal

Frontiers in Education

Received: 06 February 2017 Accepted: 26 April 2017

Published: 17 May 2017

Citation:

Asil M (2017) A School-Based Measure of Culturally Responsive

Practices.

Front. Educ. 2:17.

doi: 10.3389/feduc.2017.00017
The latest national and international assessment results [National Education Monitoring Project, National Monitoring Study of Student Achievement (NMSSA), Trends in International Mathematics and Science Study, Programme for International Student Assessment] have identified New Zealand (NZ) as having one of the widest spread of achievement among students within schools rather than between schools. Māori students in New Zealand have been identified by the Ministry of Education as a "priority learner group" because they have lower achievement outcomes, are more likely to leave school earlier without formal qualifications, and are less likely to be identified as being gifted and talented than their majority ethnic counterparts (Macfarlane, 2004; Bishop et al., 2007, 2009; Marie et al., 2008; Savage et al., 2014). To address these disparities, which are reflected at all levels of the education system, the Ministry of Education has embarked on creating culturally responsive learning environments to raise Māori student success.

The culturally responsive learning environments are an integral part of the New Zealand Curriculum (NZC) and is detailed and operationalized in various policies, publications, and initiatives, such as Ka Hikitia-Accelerating Success 2013-2017 (Ministry of Education, 2013), Te Kotahitanga (Bishop et al., 2009), Practising Teacher Criteria (Education Council New Zealand, 2015), Tātaiako: cultural Competencies for Teachers of Māori Learners (Ministry of Education, 2011), He Kākano (University of Waikato and Te Whare Wānanga o Awanuiārangi, 2010), Pasifika Education Plan (Ministry of Education, 2012a), and success for all: every school, every child (Ministry of Education, 2012b).

Previous research (Gay, 2000; Bishop et al., 2007, 2009; Macfarlane et al., 2007; Education Review Office, 2010; Meyer et al., 2010; Aronson and Laughter, 2016) has demonstrated that all students, and not only indigenous students, benefit from and perform better in culturally responsive educational settings. However, the achievement gap between Māori and non-Māori students has remained large to date (Controller and Auditor-General, 2016). In their study, Meyer et al. (2010), p. 21, argued that "there was considerable variability in the cultural responsiveness of schools, from being highly responsive to things Māori to minimal evidence of awareness of Māori students' cultural backgrounds and experiences at the school level." 


\section{Cultural Responsiveness and the New Zealand Context}

Today's schools are becoming increasingly diverse with regard to culture, language, ethnicity, religion, and socioeconomic status. Consequently, schools are challenged with providing an effective learning environment for every student in response to an increasingly diverse and multicultural student population. Culturally relevant pedagogy (Ladson-Billings, 1995), culturally responsive teaching (Gay, 2000), or culturally sustaining pedagogy (Paris, 2012) are some of the terms or concepts that appear in the education literature to emphasize collective empowerment and social justice (Aronson and Laughter, 2016) fostering and promoting educational equity and excellence in schools through cultural diversity.

Gay (2000), p. 29, defined culturally responsive teaching as "using the cultural knowledge, prior experiences, frames of reference, and performance styles of ethnically diverse students to make learning encounters more relevant and effective for them." She further notes that "being culturally responsive is more than being respectful, empathetic, or sensitive" (p. 3).

According to Gay (2013), successful implementation of culturally responsive teaching requires: eradicating the deficit view of students and communities; expecting, understanding, and resisting the opposition to culturally responsive teaching; teachers' understanding how and why culture and difference are essential ideologies and foundations; and establishing pedagogical connections between culturally responsive teaching and specific subjects and skills taught in schools. The ability of principals and teachers to engage in cultural responsiveness requires that they have a certain degree of cultural competence themselves as well (Castagno and Brayboy, 2008).

Like New Zealand, many Western educational systems continue to result in poorer learning outcomes for indigenous, minority, or vulnerable students. However, there are countries such as Japan and some Nordic countries that have more equitable learning outcomes than others (Pickett and Wilkinson, 2009), which indicate that it is achievable.

Schools need to provide high-quality teaching for heterogeneous groups of students (Alton-Lee, 2003). There is an increasing recognition of the importance of cultural responsiveness and its influence on student outcomes.

Although the Ministry of Education is continuing to build a culturally responsive education system where all children can progress and achieve to their very best, Māori and non-Māori disparity in learning outcomes persists [Organisation for Economic Co-operation and Development (OECD, 2010, 2013); Cavanagh et al., 2012; Educational Assessment Research Unit and New Zealand Council for Educational Research, 2013a,b, 2014a,b, 2015a,b]. In this regard, a closer examination of New Zealand schools' culturally responsive practices is vital to address this achievement disparity and Māori people's concerns about current pedagogic practices in mainstream schools.

\section{National Monitoring Study of Student Achievement (NMSSA)}

As part of gaining an understanding of schools' cultural responsiveness and its association with the achievement of priority learner groups, the NMSSA: Wānangatia Te Putanga Tauira developed a new self-report inventory, the Culturally Responsive Practices for Māori Scale (CRPMS), drawing on the educultural wheel (Macfarlane, 2004).

National Monitoring Study of Student Achievement is a collaboration between the Educational Assessment Research Unit at the University of Otago, the New Zealand Council for Educational Research, and the Ministry of Education. This program has been operating since 2012 with a 5-year cycle. NMSSA is sample based monitoring project designed to assess and understand student achievement at year 4 and year 8 in New Zealand primary schools.

A nationally representative sample of approximately 5,000 students in 200 schools are randomly selected across year 4 and year 8 each year to take part in NMSSA. Assessments are administered by experienced and trained teacher assessors. NMSSA uses complementary forms of assessments: group administered paper and pencil or computer-based assessments and in-depth interviews and performance assessments.

To help understand factors that are related to student achievement, contextual information is collected via student, teacher, and principal questionnaires. Approximately 600 teachers and 200 principals from participating schools are invited to respond to teacher and principal questionnaires, respectively. NMSSA has a responsibility to focus on three priority learner groups: Māori students, Pasifika students, and students with special education needs (Allan, 2012).

Most of the New Zealand research related to cultural responsiveness is qualitative in nature and uses checklists and case studies [e.g., Education Review Office (ERO)'s school evaluation indicators]. No psychometric instrument has been developed to specifically assess cultural responsiveness of schools at a national level. Therefore, a new self-report inventory, CRPMS, was developed as part of the NMSSA project.

A review of the related research literature revealed that only a few instruments have been developed specifically to measure cultural responsiveness, including Siwatu's (Siwatu, 2007) Culturally Responsive Teaching Self-Efficacy and Culturally Responsive Teaching Outcome Expectancy scales. However, these measures and most of the others elicit information from teachers regarding their beliefs or expectations rather than their practices.

The purpose of the study reported in this paper is to present the development and analysis of the factorial structure and psychometric properties of the CRPMS designed to measure and understand schools' cultural responsiveness practices in relation to Māori.

\section{Theoretical Background}

The theoretical framework for the development of CRPMS was grounded within the educultural wheel proposed by Macfarlane (2004) and guided by Ka Hikitia-Accelerating Success 20132017 (Ministry of Education, 2013).

Macfarlane's (2004) educultural wheel framework was designed to support the development of positive interactions between teachers and Māori students. It consists of five interrelated 
concepts (or factors) that encompass key aspects of culturally responsive educational settings. These concepts include: Whanaungatanga (building relationships), Manaakitanga (ethic of caring), Rangatiratanga (teacher effectiveness), Kotahitanga (ethic of bonding), and Pumanawatanga (school morale, tone, pulse). Bishop et al. (2007) are consistent with Macfarlane's (2004) model in identifying Manaakitanga and Kotahitanga for improving learning outcomes for Māori learners. According to Macfarlane (2004), p.64, "these concepts do not exist in isolation from each other-more often than not, they coexist or are amalgamated. Since Māori insist on wholeness, this is quite natural."

According to Macfarlane (2004), whanaungatanga is about building relationships with students, parents, and the community. It refers to the extent to which the school generates opportunities to build mutual respect within their school community. Manaakitanga is the extent to which the school demonstrates a "duty of care" based on kindness and respect. It is not optional but obligatory. Rangatiratanga is about developing teachers' skills and knowledge in order to develop the mana (integrity and dignity) of Māori students. Kotahitanga refers to the extent to which the school has developed practices and approaches to build a sense of unity and inclusiveness that support a culturally safe environment. Pumanawatanga is in the center of the model and represents whether the school has developed an infrastructure of care and support for students and teachers that is consistent with other four concepts.

Ka Hikitia-Accelerating Success 2013-2017 (Ministry of Education, 2013, p. 9) is the government's strategy "to rapidly change how education performs so that all Māori students gain the skills, qualifications, and knowledge they need to succeed and to be proud in knowing who they are as Māori." Ka Hikitia provides an educational framework, which guides all educational stakeholders to enable Māori students reach their full potential.

This study aimed to address a gap in current research on cultural responsiveness by introducing the CRPMS, a self-report instrument designed to measure schools' culturally responsive practices in relation to Māori students. A practical contribution of this study is to develop a useful analytical tool to inform educators and researchers on whether schools are effectively responding to the specific learning and cultural needs of Māori learners. Such information will be invaluable for education stakeholders and will also be able to contribute to the current debate on whether Māori students achieve better in schools that are more culturally responsive.

\section{MATERIALS AND METHODS}

\section{Item Generation}

The process of item generation began by reviewing the literature and empirical studies that discussed models and indicators of cultural responsiveness. To generate the initial set of items for the CRPMS, the NMSSA team worked with three local principals and discussed the nature of cultural responsiveness and current practices at their schools. At this meeting, a total of 34 Likert-type items were crafted under the five concepts. It is important to note here that all the items are about schools' practices rather than principals' beliefs.

Following this, the team took this draft to the NMSSA Māori reference group, which is a group of about 10 Māori educationalists from New Zealand including teachers, principals, ministry officials, advisors, and academic researchers who are leading figures in Māori education. The reference group members discussed and re-shaped the items within each concept quite substantially to ensure that the concepts and items validly represented the construct of culturally responsive practices for Māori students. To ensure that the items would be understood by the potential respondents (principals), the revised version was reviewed once again by the Māori reference group and Ministry of Education officials. Then the revised version was piloted with principals from a range of schools. At the end of this process, 27 items were retained for the final version and were measured on a 4 -point scale with response options of $1=$ not at all like our school, $2=$ a little like our school, $3=$ moderately like our school, and $4=$ very like our school. These 27 items were hypothesized to load on the above-mentioned five factors: Whanaungatanga, Manaakitanga, Rangatiratanga, Kotahitanga, and Pumanawatanga. The items in the CRPMS are shown in Table A1 in Appendix.

\section{Development and Validation of the CRPMS Sample}

Culturally Responsive Practices for Māori Scale items were presented to principals as part of the 2014 NMSSA principal questionnaire. Data were collected from a national sample of 199 school principals. However, 34 principals did not return a questionnaire and two principals did not respond to any of the CRPMS items. No systematic pattern was observed in the types of schools that these principals came from. Thus, responses from 163 schools ( 80 principals at year 4 and 83 at year 8 ) principals were used in this study. The distribution of these schools with regard to region and school decile was consistent with the national sample drawn for the 2014 study. The number of students attending these schools ranged from 70 to 1,361 with a mean of school size of 432 . The percentage of Māori students in each school ranged from 3 to 97 percent with a mean of 22 percent.

\section{Data Analysis}

Data analysis was conducted in two stages. First, the pattern of missing data was investigated using Little's MCAR test (Little, 1988) and the expectation maximization (EM) algorithm was used to impute missing cases. Second, the factorial structure of the CRPMS scale was assessed using confirmatory factor analysis (CFA) with robust weighted least squares mean and variance adjusted (WLSMV) estimation method. WLSMV is a robust estimation method recommended for ordinal questionnaire data (Flora and Curran, 2004).

As suggested by Noar (2003), several models were examined to compare differing conceptualizations of the factor structure. These included: (a) a null model (model 1) that assumed all of CRPMS factors are unrelated, (b) a one-factor model (model 2) that tested whether CRPMS measured one factor rather than five factors, and (c) a correlated factor model (model 3) that tested 
whether the five factors of CRPMS are related to one another. Support for model 2 would suggest that the respondents do not differentiate between the cultural responsiveness factors. That is, what is being measured is a unidimensional construct. Support for model 3 would suggest that respondents discriminate between the five factors but the factors are related to each other.

Goodness-of-model fit was assessed using a number of different indices (Cheung and Rensvold, 2002; Fan and Sivo, 2005, 2007) to reflect different aspects of model fit as not all of them are stable under various model conditions. The indices used and their commonly accepted standards of "acceptable" and/or "good" fit included:

- Due to the sensitivity of $\chi^{2}$ to sample size (Hu and Bentler, $1998)$, the ratio of $\chi^{2}$ to its degrees of freedom $\left(\chi^{2} / \mathrm{df}\right)$ with values less than 3 being indicative of an acceptable fit (Carmines and Mclver, 1981).

- Root mean square error of approximation (RMSEA) with values less than 0.08 (acceptable) or 0.05 (good).

- Comparative fit index (CFI) and Tucker-Lewis index (TLI) with values greater than 0.90 (acceptable) or 0.95 (good) (Hu and Bentler, 1998; Hair et al., 2010).

- Weighted root mean square residual (WRMR) with acceptable values being close to 1 (Yu, 2002).

\section{RESULTS}

\section{Descriptive Statistics}

The proportion of overall missing data was 2.04 percent. Little's MCAR test results for each factor suggested that the data were missing completely at random $(p>0.05)$, which supported the use of EM imputation. The descriptive statistics are presented in Table 1. The mean scores for all items ranged from 2.40 to 3.84 , suggesting that most principals indicated that the statements, on average, were "moderately like our school." The SDs ranged from 0.40 to 1.15 . The lowest mean score was observed for the Rangatiratanga statements (teacher effectiveness) whereas the highest mean score was for the Whanaungatanga statements (building relationships). Examination of the means for each concept indicated that schools had different perceptions of their culturally responsive practices. For example, the mean of teacher effectiveness concept ranged from 1 (not at all like our school) to 4 (very like our school).

\section{Confirmatory Factor Analysis}

MPlus 7 (Muthén and Muthén, 2012) was used for the CFA of each measurement model and the relationships between latent factors. The goodness-of-fit criteria of alternative models were examined. Table 2 presents the results of the model comparisons.

The CFI, TLI, and WRMR values for model 1 and model 2 did not meet the acceptable fit criteria. Among alternative models tested, a measurement model consistent with Macfarlane's framework (model 3) provided adequate fit within the recommended values of goodness-of-fit criteria and was retained as the model of best fit. For this model, factor correlations are given in Table 3 .
TABLE 1 | Descriptive statistics for culturally responsive practices for Māori scale items.

\begin{tabular}{|c|c|c|c|c|c|c|}
\hline & \multicolumn{2}{|c|}{ Item } & \multicolumn{4}{|c|}{ Factor } \\
\hline & $\mathbf{M}$ & SD & $\mathbf{M}$ & SD & Min & Max \\
\hline \multicolumn{3}{|c|}{ Pumanawatanga $(P)$} & 3.19 & 0.51 & 1.80 & 4.00 \\
\hline $\mathrm{P} 1$ & 3.55 & 0.63 & & & & \\
\hline P2 & 3.37 & 0.80 & & & & \\
\hline P3 & 3.42 & 0.68 & & & & \\
\hline P4 & 2.56 & 0.92 & & & & \\
\hline P5 & 3.03 & 0.93 & & & & \\
\hline \multicolumn{3}{|c|}{ Kotahitanga (K) } & 3.14 & 0.56 & 1.17 & 4.00 \\
\hline K1 & 3.15 & 0.81 & & & & \\
\hline $\mathrm{K} 2$ & 3.25 & 0.83 & & & & \\
\hline K3 & 3.75 & 0.66 & & & & \\
\hline K4 & 2.88 & 0.78 & & & & \\
\hline K5 & 2.48 & 1.15 & & & & \\
\hline $\mathrm{K} 6$ & 3.33 & 0.67 & & & & \\
\hline \multicolumn{3}{|c|}{ Whanaungatanga (W) } & 3.53 & 0.41 & 2.20 & 4.00 \\
\hline W1 & 3.75 & 0.48 & & & & \\
\hline W2 & 3.23 & 0.74 & & & & \\
\hline W3 & 3.24 & 0.74 & & & & \\
\hline W4 & 3.84 & 0.40 & & & & \\
\hline W5 & 3.62 & 0.58 & & & & \\
\hline \multicolumn{3}{|c|}{ Manaakitanga (M) } & 3.24 & 0.51 & 1.50 & 4.00 \\
\hline M1 & 2.79 & 0.75 & & & & \\
\hline M2 & 3.63 & 0.62 & & & & \\
\hline M3 & 3.01 & 0.86 & & & & \\
\hline M4 & 3.54 & 0.73 & & & & \\
\hline \multicolumn{3}{|c|}{ Rangatiratanga (R) } & 2.79 & 0.64 & 1.00 & 4.00 \\
\hline $\mathrm{R} 1$ & 3.36 & 0.70 & & & & \\
\hline $\mathrm{R} 2$ & 2.90 & 1.11 & & & & \\
\hline R3 & 3.13 & 0.83 & & & & \\
\hline R4 & 2.40 & 1.04 & & & & \\
\hline R5 & 2.79 & 0.93 & & & & \\
\hline R6 & 2.47 & 0.93 & & & & \\
\hline $\mathrm{R} 7$ & 2.49 & 0.96 & & & & \\
\hline
\end{tabular}

TABLE 2 | Confirmatory factor analysis of alternative models.

\begin{tabular}{lcccccc}
\hline Model & $\chi^{2}$ & $\chi^{2} / \mathbf{d f}$ & RMSEA $(\mathbf{9 0} \% \mathbf{C I})$ & $\mathbf{C F I}$ & TLI & WRMR \\
\hline $\begin{array}{l}\text { Model 1 } \\
\text { (null model) }\end{array}$ & $1,942.56$ & 5.99 & $0.18(0.17,0.18)$ & 0.36 & 0.31 & 3.25 \\
$\begin{array}{l}\text { Model 2 } \\
\text { (one-factor) }\end{array}$ & 653.71 & 2.02 & $0.08(0.07,0.09)$ & 0.87 & 0.86 & 1.25 \\
$\begin{array}{l}\text { Model 3 (five-factor } \\
\text { correlated) }\end{array}$ & 523.05 & 1.67 & $0.06(0.05,0.07)$ & 0.92 & 0.91 & 1.06 \\
\hline
\end{tabular}

RMSEA, root mean square error of approximation; CFI, comparative fit index; TLI, Tucker-Lewis Index; WRMR, weighted root mean square residual.

The correlations between CRPMS factors ranged from 0.52 to 0.90 indicating that the evidence for discriminant validity was not strong. However, the level of relationship amongst factors was consistent with Macfarlane's theory of "wholeness" appropriate for Māori cultural responsiveness. The highest correlations were found between Kotahitanga and Pumanawatanga, and Kotahitanga and Manaakitanga.

The unstandardized and standardized factor loadings and factor reliabilities are presented in Table 4. The limitations and problems of coefficient alpha (Cronbach, 1951) as a measure of reliability estimate is well established in the literature (Sijtsma, 2009; Teo and 
TABLE 3 | Culturally responsive practices for Māori scale factor correlations.

\begin{tabular}{lccccc}
\hline & P & K & W & M & R \\
\hline Pumanawatanga (P) & - & & & & \\
Kotahitanga (K) & 0.90 & - & & & \\
Whanaungatanga (W) & 0.53 & 0.52 & - & & \\
Manaakitanga (M) & 0.76 & 0.86 & 0.76 & - & - \\
Rangatiratanga (R) & 0.73 & 0.77 & 0.54 & 0.77 & \\
\hline
\end{tabular}

TABLE 4 | Unstandardized and standardized factor loadings and reliabilities.

\begin{tabular}{|c|c|c|c|c|}
\hline Item & $\begin{array}{c}\text { Unstandardized } \\
\text { estimate }\end{array}$ & $\begin{array}{c}\text { Standardized } \\
\text { estimate }\end{array}$ & $\begin{array}{l}\text { Coefficient } \\
\text { alpha }\end{array}$ & glb \\
\hline Pumanawatanga $(\mathrm{P})$ & & & 0.68 & 0.74 \\
\hline P1 & 1.00 & 0.73 & & \\
\hline P2 & 0.79 & 0.64 & & \\
\hline P3 & 0.35 & 0.35 & & \\
\hline P4 & 0.71 & 0.60 & & \\
\hline P5 & 0.61 & 0.54 & & \\
\hline Kotahitanga (K) & & & 0.79 & 0.82 \\
\hline $\mathrm{K} 1$ & 1.00 & 0.80 & & \\
\hline $\mathrm{K} 2$ & 0.73 & 0.69 & & \\
\hline $\mathrm{K} 3$ & 0.42 & 0.49 & & \\
\hline K4 & 1.13 & 0.83 & & \\
\hline $\mathrm{K} 5$ & 0.45 & 0.51 & & \\
\hline K6 & 0.72 & 0.69 & & \\
\hline Whanaungatanga (W) & & & 0.81 & 0.85 \\
\hline W1 & 1.00 & 0.46 & & \\
\hline W2 & 3.24 & 0.86 & & \\
\hline W3 & 1.42 & 0.59 & & \\
\hline W4 & 2.15 & 0.75 & & \\
\hline W5 & 2.12 & 0.74 & & \\
\hline Manaakitanga (M) & & & 0.68 & 0.72 \\
\hline M1 & 1.00 & 0.60 & & \\
\hline M2 & 1.36 & 0.72 & & \\
\hline M3 & 0.79 & 0.51 & & \\
\hline M4 & 1.20 & 0.67 & & \\
\hline Rangatiratanga (R) & & & 0.80 & 0.86 \\
\hline $\mathrm{R} 1$ & 1.00 & 0.65 & & \\
\hline $\mathrm{R} 2$ & 0.99 & 0.65 & & \\
\hline R3 & 0.93 & 0.63 & & \\
\hline R4 & 0.69 & 0.51 & & \\
\hline R5 & 1.16 & 0.71 & & \\
\hline $\mathrm{R} 6$ & 2.04 & 0.87 & & \\
\hline $\mathrm{R} 7$ & 1.98 & 0.86 & & \\
\hline
\end{tabular}

glb, greatest lower bound.

Fan, 2013), but this index is still widely used. Therefore, the greatest lower bound (glb) to reliability (Jackson and Agunwamba, 1977; Woodhouse and Jackson, 1977) was calculated and reported as a better estimate of reliability (Ten Berge and Sočan, 2004; Sijtsma, 2009). Greatest lower bound estimates were computed by means of the FACTOR program (Lorenzo-Seva and Ferrando, 2006), which can be downloaded from http://psico.fcep.urv.es/utilitats/ factor/Download.html. Sijtsma (2009), however, states that alpha should also be used alongside glb as a better practice for reporting reliability (p. 118). This is the procedure followed in this study.

All item parameter estimates were statistically significant at $p<0.001$ level. Factor loadings ranged from 0.35 to 0.86 , which provided support for convergent validity evidence. Two of the coefficient alpha reliability estimates were slightly less than the recommended level (0.70) for instrument development. Given the small number of items for those factors; however, these values were considered acceptable. On the other hand, all glb estimates were greater than the 0.70 threshold. The CFA analyses, factor correlations, and reliabilities provided support for the factorial and construct validity evidence of the CRPMS.

\section{DISCUSSION AND CONCLUSION}

The aim of this study was to provide validity evidence on the internal structure of the CRPMS self-report instrument designed by the NMSSA team to measure the degree to which New Zealand English-speaking primary schools were culturally responsive to Māori students. The present study adds to the culturally responsive education research literature specifically by providing empirical evidence via CFA supporting the factorial structure of the CRPMS comprising five factors: Whanaungatanga (building relationships), Manaakitanga (ethic of caring), Rangatiratanga (teacher effectiveness), Kotahitanga (ethic of bonding), and Pumanawatanga (school morale, tone, pulse). In general, the validity evidence findings from this study support the utility of CRPMS as a measure of cultural responsiveness for mainstream New Zealand schools.

In line with the previous findings of Meyer et al. (2010), we found that school principals had different perceptions/interpretations of their schools' culturally responsive practices. The range of school means for CRPMS constructs indicated that there was some variability between schools with respect to cultural responsiveness practices. In general, however, the overall scale means revealed that most principals responded as either or "moderately like our school" or "very like our school."

It is important to note that this is a bold project that spans a significant breadth of literature. What becomes difficult to preserve is the rich conceptual depth of tea o Māori/Māori worldview, which may be diluted by attempts at analytical specificity. The moderate-to-high correlations among the five factors of the CRPMS suggest that these factors tapped distinct but interrelated aspects of the same construct, which is consistent with Macfarlane's (Macfarlane, 2004) theory.

This study supports Sleeter's (Sleeter, 2012), p. 578, claims that "small-scale case studies illustrate what is possible, but we also need research on the impact of scaled-up work in culturally responsive pedagogy, including research showing how teachers can learn to use it in their classrooms." This study has several important implications. First, gaining a better understanding of schools' culturally responsive practices will increase our understanding of its nature and its relationship to student learning outcomes. Such knowledge has relevance for educators and researchers in bilingual, multilingual, and multicultural societies. Second, this CRPMS instrument may be used in a school's self-review by principals and teachers rating their schools' relative strengths and weaknesses in their responsiveness to Māori students and identifying areas that need to be addressed. This is particularly important given that the ERO (Education Review Office, 2010, p. 1) reported that "not all educators have yet recognized their professional responsibility to provide a learning environment that promotes success for Māori students." Third, CRPMS outcomes 
may provide empirical evidence that can guide school policy decisions, which may lead to more satisfaction with school by Māori students as Māori.

Further replication and validation studies with the CRPMS is needed to provide further evidence for its validity in different settings. Research is also necessary to investigate the relationships between the CRPMS and significant student outcomes, and how this measure can be used with teachers who have the potential to change the educational outcomes of Māori students (Hattie, 2008). We believe that further replication and validation studies are needed to make sure that the instrument works well in different settings. Although developed for Māori cultural responsiveness, this model may be able to be adapted for other ethnic groups reflecting their cultural perspectives.

Cultural responsiveness in an important component of the ERO's school evaluation indicators. As part of their review process, ERO evaluates schools and makes recommendations regarding their responsiveness to the needs of Māori students. Further studies may use ERO reports to CRPMS results.

One limitation of the study is the marginal sample size available in this study. As mentioned in the literature (Fan and Sivo, 2007), various fit indices and parameter estimates are sensitive to sample size. The other limitation pertains to a possible response bias that may exist in principals' responses. Principals may have provided socially desirable responses. Future research may consider collecting cultural responsiveness data by means of independent ratings (e.g., ERO) or multiple ratings from the

\section{REFERENCES}

Allan, R. (2012). National monitoring study of student achievement: wanangatia te putanga tauira. Set: Res. Info. Teach. 3, 78-80.

Alton-Lee, A. (2003). Quality Teaching for Diverse Students in Schooling: Best Evidence Synthesis. Wellington: Ministry of Education.

Aronson, B., and Laughter, J. (2016). The theory and practice of culturally relevant education A synthesis of research across content areas. Rev. Educ. Res. 86, 163-206. doi:10.3102/0034654315582066

Bishop, R., Berryman, M., Cavanagh, T., and Teddy, L. (2007). Te Kotahitanga Phase 3: Establishing a Culturally Responsive Pedagogy of Relations in Mainstream Secondary School Classrooms. Wellington, New Zealand: Ministry of Education.

Bishop, R., Berryman, M., Cavanagh, T., and Teddy, L. (2009). Te kotahitanga: addressing educational disparities facing Māori students in New Zealand. Teach. Teach. Educ. 25, 734-742. doi:10.1016/j.tate.2009.01.009

Carmines, E. G., and Mclver, J. P. (1981). "Analyzing models with unobserved variables: analysis of covariance structures," in Social Measurement: Current Issues, eds W. B. George and F. B. Edgar (Beverly Hills, CA: SAGE), 65-115.

Castagno, A. E., and Brayboy, B. M. J. (2008). Culturally responsive schooling for indigenous youth: a review of the literature. Rev. Educ. Res. 78, 941-993. doi:10.3102/0034654308323036

Cavanagh, T., Macfarlane, A., Glynn, T., and Macfarlane, S. (2012). Creating peaceful and effective schools through a culture of care. Discourse Stud. Cult. Polit. Educ. 33, 443-455. doi:10.1080/01596306.2012.681902

Cheung, G. W., and Rensvold, R. B. (2002). Evaluating goodness-of-fit indexes for testing measurement invariance. Struct. Equ. Model. 9, 233-255. doi:10.1207/ S15328007SEM0902_5

Controller and Auditor-General. (2016). Education for Māori: Using Information to Improve Māori Educational Success. Available at: http://www.oag.govt.nz/2016/ education-for-maori

Cronbach, L. J. (1951). Coefficient alpha and the internal structure of tests. Psychometrika 16, 297-334. doi:10.1007/BF02310555 school community, such as teachers, students, whanau, and/or iwi rather than relying only on principals' self-reporting.

\section{ETHICS STATEMENT}

This study was approved by the "University of Otago Human Ethics Committee."

\section{AUTHOR CONTRIBUTIONS}

CRPMS was developed by the National Monitoring Study of Student Achievement (NMSSA) team. The author designed this validation study, developed the methodology, performed the analysis, and wrote the manuscript. The author agrees to be accountable for all aspects of the work.

\section{ACKNOWLEDGMENTS}

The author wish to acknowledge the support and contributions of Alison Gilmore, Denise Quinlan, and NMSSA project team and thank all principals, teachers, and students who participated in the 2014 NMSSA study.

\section{FUNDING}

The National Monitoring Study of Student Achievement (NMSSA) project is funded by the Ministry of Education, New Zealand.

Education Council New Zealand. (2015). Practising Teacher Criteria. Available at: http://educationcouncil.org.nz/content/practising-teacher-criteria

Education Review Office. (2010). Promoting Success for Māori Students: Schools Progress. Wellington, New Zealand. Available at: http://www.ero.govt.nz/assets/ Uploads/Promoting-Success-for-Maori-Students-Schools-Progress-2010.pdf

Educational Assessment Research Unit, and New Zealand Council for Educational Research. (2013a). National Monitoring Study of Student Achievement: Science 2012. Wellington: Ministry of Education.

Educational Assessment Research Unit, and New Zealand Council for Educational Research. (2013b). National Monitoring Study of Student Achievement: English: Writing 2012. Wellington: Ministry of Education.

Educational Assessment Research Unit, and New Zealand Council for Educational Research. (2014a). National Monitoring Study of Student Achievement: Health and Physical Education 2013. Wellington: Ministry of Education.

Educational Assessment Research Unit, and New Zealand Council for Educational Research. (2014b). National Monitoring Study of Student Achievement: Mathematics and Statistics 2013. Wellington: Ministry of Education.

Educational Assessment Research Unit, and New Zealand Council for Educational Research. (2015a). National Monitoring Study of Student Achievement: English: Reading 2014 - Overview. Wellington: Ministry of Education.

Educational Assessment Research Unit, and New Zealand Council for Educational Research. (2015b). National Monitoring Study of Student Achievement: Social Studies 2014 - Overview. Wellington: Ministry of Education.

Fan, X., and Sivo, S. A. (2005). Sensitivity of fit indexes to misspecified structural or measurement model components: rationale of two-index strategy revisited. Struct. Equ. Model. 12, 343-367. doi:10.1207/s15328007sem1203_1

Fan, X., and Sivo, S. A. (2007). Sensitivity of fit indices to model misspecification and model types. Multivariate Behav. Res. 42, 509-529. doi: $10.1080 / 00273170701382864$

Flora, D. B., and Curran, P. J. (2004). An empirical evaluation of alternative methods of estimation for confirmatory factor analysis with ordinal data. Psychol. Methods 9, 466. doi:10.1037/1082-989X.9.4.466 
Gay, G. (2000). Culturally Responsive Teaching: Theory, Research, and Practice. New York: Teachers College Press.

Gay, G. (2013). Teaching to and through cultural diversity. Curric. Inq. 43, 48-70. doi:10.1111/curi.12002

Hair, J. F. Jr., Black, W. C., Babin, B. J., and Anderson, R. E. (2010). Multivariate Data Analysis, 7th Edn. New York, NY: Prentice Hall.

Hattie, J. (2008). Visible Learning: A Synthesis of Over 800 Meta-Analyses Relating to Achievement. London: Routledge.

$\mathrm{Hu}, \mathrm{L}$., and Bentler, P. M. (1998). Fit indices in covariance structure modeling: sensitivity to underparameterized model misspecification. Psychol. Methods 3, 424-453. doi:10.1037/1082-989X.3.4.424

Jackson, P. H., and Agunwamba, C. C. (1977). Lower bounds for the reliability of the total score on a test composed of non-homogeneous items: I: algebraic lower bounds. Psychometrika 42, 567-578. doi:10.1007/BF02295979

Ladson-Billings, G. (1995). Toward a theory of culturally relevant pedagogy. Am. Educ. Res. J. 32, 465-491. doi:10.3102/00028312032003465

Little, R. J. (1988). A test of missing completely at random for multivariate data with missing values. J. Am. Stat. Assoc. 83, 1198-1202. doi:10.1080/01621459. 1988.10478722

Lorenzo-Seva, U., and Ferrando, P. J. (2006). FACTOR: a computer program to fit the exploratory factor analysis model. Behav. Res. Methods 38, 88-91. doi:10.3758/BF03192753

Macfarlane, A., Glynn, T., Cavanagh, T., and Bateman, S. (2007). Creating culturally-safe schools for Māori students. Aust. J. Indigen. Educ. 36, 65-76. doi:10.1017/S1326011100004439

Macfarlane, A. H. (2004). Kia hiwa ra: Listen to Culture: Māori Students' Plea to Educators. Wellington: New Zealand Council for Educational Research.

Marie, D., Fergusson, D. M., and Boden, J. M. (2008). Educational achievement in Māori: the roles of cultural identity and social disadvantage. Aust. J. Educ. 52, 183-196. doi:10.1177/000494410805200206

Meyer, L. H., Penetito, W., Hynds, A., Savage, C., Hindle, R., and Sleeter, C. E. (2010). Evaluation of the Te Kotahitanga Programme, Final Report. Wellington, New Zealand: Ministry of Education.

Ministry of Education. (2011). Tātaiako: Cultural Competencies for Teachers of Māori Learners. Wellington, New Zealand: Ministry of Education.

Ministry of Education. (2012a). Pasifika Education Plan 2013-2017. Wellington, New Zealand: Ministry of Education.

Ministry of Education. (2012b). Success for All: EverySchool, Every Child. Available at: http://www.education.govt.nz/school/running-a-school/inclusive-education/

Ministry of Education. (2013). Ka Hikitia-Accelerating Success 2013-2017: The Māori Education Strategy. Wellington, New Zealand: Ministry of Education.

Muthén, L. K., and Muthén, B. O. (2012). Mplus: Statistical Analysis with Latent Variables: User's Guide. Los Angeles, CA: Muthén \& Muthén.

Noar, S. M. (2003). The role of structural equation modeling in scale development. Struct. Equ. Modeling 10, 622-647.

Organisation for Economic Co-operation and Development (OECD). (2010). PISA 2009 Results: Overcoming Social Background: Equity in Learning Opportunities and Outcomes, Vol. II. Paris, France: OECD.
Organisation for Economic Co-operation and Development (OECD). (2013). PISA 2012 Results: Excellence Through Equity: Giving Every Student the Chance to Succeed, Vol. II. Paris, France: OECD.

Paris, D. (2012). Culturally sustaining pedagogy a needed change in stance, terminology, and practice. Educ. Res. 41, 93-97. doi:10.3102/0013189X12441244

Pickett, K., and Wilkinson, R. (2009). The Spirit Level: Why More Equal Societies Almost Always do Better. London: Allen Lane.

Savage, C., Macfarlane, S., Macfarlane, A., Fickel, L., and Te Hēmi, H. (2014). Huakina Mai: a Kaupapa Māori approach to relationship and behaviour support. Aust. J. Indigen. Educ. 43, 165-174. doi:10.1017/jie.2014.23

Sijtsma, K. (2009). On the use, the misuse, and the very limited usefulness of Cronbach's alpha. Psychometrika 74, 107-120. doi:10.1007/s11336-0089101-0

Siwatu, K. O. (2007). Preservice teachers' culturally responsive teaching selfefficacy and outcome expectancy beliefs. Teach. Teach. Educ. 23, 1086-1101. doi:10.1016/j.tate.2006.07.011

Sleeter, C. E. (2012). Confronting the marginalization of culturally responsive pedagogy. Urban Educ. 47, 562-584. doi:10.1177/0042085911431472

Ten Berge, J. M. F., and Sočan, G. (2004). The greatest lower bound to the reliability of a test and the hypothesis of unidimensionality. Psychometrika 69, 613-625. doi:10.1007/BF02289858

Teo, T., and Fan, X. (2013). Coefficient alpha and beyond: issues and alternatives for educational research. Asia Pac. Educ. Res. 22, 209-213. doi:10.1007/ s40299-013-0075-z

University of Waikato and Te Whare Wānanga o Awanuiārangi. (2010). He Kākano: Te awe o ngātoroa: A School Based Programme for the Development of Culturally Responsive Leaders. Waikato, New Zealand: University of Waikato \& Te Whare Wānanga o Awanuiārangi.

Woodhouse, B., and Jackson, P. H. (1977). Lower bounds for the reliability of the total score on a test composed of non-homogeneous items: II: a search procedure to locate the greatest lower bound. Psychometrika 42, 579-591. doi:10.1007/BF02295980

Yu, C. Y. (2002). Evaluating Cut-Off Criteria of Model Fit Indices for Latent Variable Models with Binary and Continuous Outcomes [Doctoral Dissertation]. University of California Los Angeles.

Conflict of Interest Statement: The author declares that the research was conducted in the absence of any commercial or financial relationships that could be construed as a potential conflict of interest.

The reviewer, JS, declared a shared affiliation, though no other collaboration, with the author to the handling editor, who ensured that the process nevertheless met the standards of a fair and objective review.

Copyright (C) 2017 Asil. This is an open-access article distributed under the terms of the Creative Commons Attribution License (CC BY). The use, distribution or reproduction in other forums is permitted, provided the original author(s) or licensor are credited and that the original publication in this journal is cited, in accordance with accepted academic practice. No use, distribution or reproduction is permitted which does not comply with these terms. 


\section{APPENDIX}

\section{TABLE A1 | Culturally responsive practices for Māori scale.}

Pumanawatanga (P)

P1

The school provides an appropriate and welcoming environment for Māori students and visitors (including visual displays, appropriate use of pōwhiri, and mihi whakatau as agreed to)

P2 Karakia and waiata are included in school gatherings and their role is understood by students and teachers We are successfully able to engage with our students whānau in consultation (e.g., parent teacher and other school meetings and activities)

P4

We are successfully able to engage with hapū and iwi in consultation and whole school marae visits are a regular component of the school curriculum

P5 Māori whānau are attracted to this school and actively seek to enroll their children here

Kotahitanga $(\mathrm{K})$ K1

School-wide planning incorporates Māori perspectives through ongoing collaboration and consultation, which has led to change

$\mathrm{K} 2$

The school actively engages in Māori community events and celebrations, such as Matariki and Te wiki o te reo Māori

K3

All students are offered the opportunity to participate in Kapa haka

K4

Individual curriculum areas reflect an authentic and contemporary Māori world-view and include innovative resources and topics that meet the priorities and goals expressed by the school's Māori students and their whānau group

K5 Intensive te reo Māori study options are available to students

K6 Teachers and the wider school community appreciate the value of te reo and tikanga Ma-ori for all students

Whanaungatanga (W) W1

Teachers get to know all students and learn about their family context

W2 Staff successfully build strong relationships with Māori students and their whānau, having implemented ideas from the school's whānau group

W3

Tuakana/teina relationships are in place throughout the school

Māori students know their teachers care about them and have high expectations for them, and teachers communicate this to them

W5
Staff provide opportunities in class for students to use their prior knowledge and experiences and to share their world views and knowledge in ways that enhance learning

\section{TABLE A1 | Continued}

Manaakitanga (M)

M1

M2

M3

M4

$\mathrm{R} 2$

R3

R4

R5

R6

$\mathrm{R} 7$

Rangatiratanga $(\mathrm{R})$ R1
All school staff members know te reo Māori names of the waka, mountains, rivers, iwi, hapū, marae, and places in the school area

All staff and students are strongly encouraged to correctly pronounce Māori student names and place names

Māori-centered restorative justice approaches are used to hear different parties' perspectives and restore relationships

Māori achievement in academic and other areas such as leadership, performance, and oratory is explicitly celebrated, valued, and encouraged

The school is meeting the specific short, medium, and long-term goals for Māori students set out in our strategic plan, and informed by Ka Hikitia Accelerating Success, 2013-2017, the Māori Education Strategy The school has successfully encouraged Māori representation on the school board that provides a valued and informed Māori voice and leadership Teachers are encouraged and supported to learn te reo Māori

Some teachers are fluent in te reo Māori

Teachers have ongoing professional development on Māori perspectives including equity issues relating to the Treaty of Waitangi

Systems developed with the school's Māori whānau group/Māori advisors to check that school resources are culturally appropriate for Māori students, are in place, and working

Decision-making and resources regarding Māori education programs are made with the school's Māori whānau group/Māori advisors 